\title{
Open data and its usability: an empirical view from the Citizen's perspective
}

\author{
Vishanth Weerakkody ${ }^{1}$ - Zahir Irani ${ }^{1} \cdot$ Kawal Kapoor $^{1} \cdot$ Uthayasankar Sivarajah $^{1}$. \\ Yogesh K. Dwivedi ${ }^{2}$
}

Published online: 23 July 2016

(C) The Author(s) 2016. This article is published with open access at Springerlink.com

\begin{abstract}
Government legislation and calls for greater levels of oversight and transparency are leading public bodies to publish their raw datasets online. Policy makers and elected officials anticipate that the accessibility of open data through online Government portals for citizens will enable public engagement in policy making through increased levels of fact based content elicited from open data. The usability and benefits of such open data are being argued as contributing positively towards public sector reforms, which are under extreme pressures driven by extended periods of austerity. However, there is very limited scholarly studies that have attempted to empirically evaluate the performance of government open data websites and the acceptance and use of these data from a citizen perspective. Given this research void, an adjusted diffusion of innovation model based on Rogers' diffusion of innovations theory (DOI) is proposed and used in this paper to empirically determine the predictors influencing the use of public sector open data. A good understanding of these predictors affecting the acceptance and use of open data will likely assist policy makers and public
\end{abstract}

Vishanth Weerakkody

Vishanth.Weerakkody@brunel.ac.uk

Zahir Irani

Zahir.irani@brunel.ac.uk

Kawal Kapoor

Kawal.Kapoor@brunel.ac.uk

Uthayasankar Sivarajah

Sankar.Sivarajah@brunel.ac.uk

Yogesh K. Dwivedi

y.k.dwivedi@swansea.ac.uk

1 Business School, Brunel University London, Uxbridge, UK

2 School of Management, Swansea University, Swansea, UK administrations in determining the policy instruments that can increase the acceptance and use of open data through an active promotion campaign to engage-contribute-use.

Keywords Open data · Government · Policy · Citizens · Usability

\section{Introduction}

Open and accessible data revolution is underway. Citizens no longer want to be passive recipients of legislation that is considered 'inflicted' upon them but rather, seek constructive ways to engage-contribute-use the formation of public policy as a means to enhance their civic responsibilities. However, for this to happen, any engagement needs to orientate around evidence that is underpinned by facts elicited from open sources of big data. Consequentially, public engagement is reshaping how knowledge is developed, shared and used by citizens and stakeholder communities.

The push for making public services data available to the community started around mid- 2000s with the European Union directive encouraging greater realisation of the economic value of public data through its reuse in 2003. Conventionally, government departments retained public service data within their systems, with limited information being released to citizens and other stakeholders (i.e. businesses, charitable organizations, and NGO communities). However, the spread of digital governance and associated norms, such as responsiveness, accessibility and efficiency of public services, transparency and accountability (Carter and Weerakkody 2008; Wilcox 2010; Rana et al. 2015), have motivated governments to exploit the potential of wider distribution and use of such data (Sivarajah et al. 2015, 2016).

The United States (US) is one of the first countries to mandate the use of open data in December 2009. Six months later, 
United Kingdom (UK) followed with their own plans to open public data, with the Prime Minister announcing the setting up of the data.gov.uk website. Subsequently, the European Commission published a Communication on Open Data in 2011, and in the same year, US, UK, and initially six other countries were signatories to the Open Government Declaration. UK is considered as one of the leading countries in Europe for open data. The data.gov.uk website is one of the most comprehensive open data repositories making available non-personal UK government data about public services, ranging from health, social services, education, transport to crime and other geo-environmental data.

Although countries such as the UK and US have taken proactive steps to improve the availability and ease of use of data (through machine-readability and technical standards), there still remain several barriers orientated around human, organisational and technological factors to accessibility and usability of open data that prevent its widespread proliferation. Moreover, the actual structuring and interrogation of open data is cumbersome and often requires detailed analytical skills. To fully exploit the potential of open data, users will usually require a certain level of technical skills. The fact that there is no existing easy-to-use, proven solution, which can help citizens exploit open data for decision making (affecting day-to-day activities), or contribute to the wider public policy making debate, does not promote the widespread take-up of open data sources. Such issues are further compounded by the generic nature of open data repositories such as www.data. gov.uk and www.epsiplatform.eu, and thus their relevance and direct interest to citizens, in particular.

The motivation for this paper lies in the reasoning that although the availability of open data offers many opportunities for citizens, no research exists that questions the usability of open data platforms, particularly from a citizen's perspective. As a result, this research contributes to the public sector and open data literature by proposing an adjusted diffusion of innovation model based on Rogers' diffusion of innovations theory (DOI) to empirically determine the predictors influencing the use of public sector open data. The paper is structured as follows: next section of the paper reviews the literature offering an overview of open data. The following section presents a discussion surrounding the development of the research model and the hypotheses that have been proposed as part of this study. The research method is then explained in the subsequent section, followed by the analysis of empirical data and discussion of the findings. The paper concludes by outlining the main contributions and acknowledging the limitations of this study.

\section{Literature context: an overview of open data}

The goal of Open Data initiatives has been to open all nonpersonal and non-commercial data, especially data collected and processed by government organizations (Braunschweig et al. 2012). Public sector organisations have started making governmental data available on web portals, as web services, so that the public have access to such official datasets in one place. The increase in availability of open data initiatives has been seen mainly due to the growing pressure imposed by governments on all kinds of public organisations to release their raw data (Sivarajah et al. 2016; Janssen et al. 2012). The key motivators encouraging public organisations to publish data revolves around government's perception that the open access to publicly-funded data provides: (a) greater economic returns from public investment (Cranefield et al. 2014), (b) access to policy-makers with data needed to address complex problems (Sivarajah et al. 2016; Arzberger et al. 2004), (c) generates wealth through the downstream use of outputs (Janssen et al. 2012), and (d) helps involve citizens in analysing large quantities of datasets (Surowiecki 2004).

Using open data can provide several advantages to civil servants, citizens and other stakeholders, such as increased transparency and accountability (Rose et al. 2015; Cranefield et al. 2014; Bertot et al. 2010), stimulating innovation (van Veenstra and van den Broek 2013; Janssen et al. 2012), and increased participation of citizens in government activities (Castellanos et al. 2013; Conradie and Choenni 2014; McDermott 2010). One of the most notable advantage of open data is that making government data transparent increases public trust in government and civil servants, and also allows citizens to hold the government officials accountable (Cranefield et al., 2014; Ubaldi, 2013; Janssen et al., 2012). Scholars such as Borzacchiello and Craglia (2012) and Janssen et al. (2012) have asserted, open data can have a positive impact on economic growth by, for example, encouraging the marketplace to develop products and services, which increases productivity, offering employment, and bringing revenue back to government in the form of taxation revenue. Apart from economic benefits, Ubaldi (2013) highlights, open data also has societal benefits as it allows citizens to interact with government in an informed and interactive manner. According to Cranefield et al. (2014), opening data can also lead to improved data quality via crowdsourcing of corrections or by filling gaps in data.

Although open data can potentially provide considerable benefits, its use also comes with a number of drawbacks. Some of the key challenges are - increasing public interest, cost involved in opening up data, data ownership risk, legality and privacy issues (Weerakkody et al. 2015; Dwivedi et al. 2015; Osman et al. 2014). Scholars such as Ubaldi (2013) and Zuiderwijk et al. (2012) assert that one of the most significant challenge is stimulating public interest in using open data effectively. Then, there is the cost of opening up of data (Cranefield et al. 2014 and Ubaldi 2013), especially as they are often experienced as upfront costs thus calling for the need for robust approached to evaluation (Sharif et al. 2010; Irani 
et al. 2014). Data quality concern is also another key issue as government departments may be reluctant to release data that they see as low quality (Conradie and Choenni 2014). Zuiderwijk and Janssen (2014) suggest that data ownership risks and legality concerns are major challenges of open data. In addition, there is also the risk of privacy violation.

One of the key purposes of open data platforms is to promote access to government data and encourage development of creative tools and applications to engage and serve the wider community through the visualisation of patterns and relationships (Martín et al. 2015; Irani et al. 2014; Kassen 2013). In doing so, enabling civic engagement by providing opportunity for citizens, public sector organisations, businesses and independent developers to use systematically-updated stream of open data is being encouraged. The governments perceive that making this data available on the web would lead to more transparency, participation, and innovation throughout society (Conradie and Choenni 2014; Veljković et al. 2014; Janssen et al. 2012; Bertot et al. 2012; Choenni et al. 2010). Governments and publishers of open data expect the users to exploit such data in as many ways as possible for the benefit of the society (Data.gov.uk 2015). For example, general public (nontechnical users) may use it to analyse trends in one policy area over time, or compare how different parts of the government go about doing their work (Sivarajah et al. 2016). On the other hand, technical users such as software developers are encouraged to create useful applications out of the raw data files, which can then be used by everyone benefitting the wider society.

The way people access and use open data is greatly influenced by the way data is published (Braunschweig et al. 2012). In its original, raw form, this data is often not very useful for end users. Therefore, datasets are cleaned and customized before being published. Apart from accessing data from these platforms, users (e.g. organisations) are also encouraged to submit useful data that can be published to the general public. One of the challenges is making existing data come to life, and users are encouraged to combine and reorganise existing data to offer new insights resulting in useful visualisations of these data (Data.gov.uk 2015). Despite occasional initiatives from the government to encourage the use of open data technologies via events such as hackathons, workshops and conferences, not much is known about the predictors which influence people's (i.e. citizens) perceptions, willingness, ability and intention to use open data technologies. Open data is an emerging field and the acceptance and use of open data technologies has not received much attention in the extant literature.

\section{Research model and hypotheses development}

The Diffusion of Innovation (DOI) model, derived from Rogers' DOI theory can suitably examine the acceptance and use of open data in the public sector, as it allows for examining citizen perceptions, whilst identifying factors that influence their acceptance decisions concerning the use of open data. Moreover, the DOI model allows for investigating the complex user adoption process, as the model attributes account for up to $49 \%-87 \%$ variance in the adoption rate (Rogers 2003). Open data is composed of varying contexts and connotations of open datasets. These datasets are characteristically and contextually different and involve a wide array of interdependent stakeholders with varying interests. Open data, currently available in the raw format, can be fairly complex for users to understand and use. The DOI model focuses on aspects such as - how relatively advantageous is the proposed solution to the existing methods, and how easy to use technologies are important in positively influencing consumers' use decisions. Literature extensively supports the use of DOI attributes in measuring an innovative solution that is aiming to attract consumer usage based on the aspects of usefulness, ease of use, and compatibility (Moore and Benbasat 1991; Karahanna et al. 1999; Tan and Teo 2000; Rijsdijk and Hultink 2003; Pannell et al. 2006; Kapoor et al. 2013). This thus enhances the appropriateness of the Diffusion of Innovation model being employed by this study to evaluate the user perceptions of the usability of public sector open data.

According to Stokes et al. (2014), adoption studies in private sector have created a clear language and a set of frameworks for understanding innovation adoptions. Some field experts have their reservations about these frameworks and they identify them as being stereotypical, without sufficient empirical support or understanding of the intricate nature of the innovation adoption process (Stokes et al. 2014). Ongoing research is now extending to account for not only the organizational, systemic, and contextual effects, but also the push and pull effects of the innovators and the innovation adopters. To the best of authors' knowledge, there is no study analysing the factors affecting citizens' intentions to adopt open data. Studies like Zuiderwijk et al. (2015) have studied the acceptance and use of open data technologies, but no study places clear emphasis on the citizens' intention to adopt open data itself.

Extant literature highlights that very few studies have attempted to empirically evaluate the performance of open data websites. There are, however, evidences of other studies using different measures of innovation adoption to investigate the performance of different websites. For instance, Wangpipatwong et al. (2008) use the Technology Acceptance Model (TAM) alongside self-efficacy as an added measure, to evaluate the use of an e-government website. Fang and Holsapple (2007) focus on the navigation structure of a website and their impact on the usability of that website by using factors defining its usability. Wang and Senecal (2007) used ease of use, speed, and interactivity to measure the usability of a website and its subsequent impact on user attitudes and 
intentions. Wang et al. (2001) empirically study consumers' satisfaction of a website dealing with digital products and services using beliefs and attitudinal constructs.

According to Zuiderwijk et al. (2015), the acceptance and use of Information Technology has been significantly important from the IS research and practice perspectives. The DOI model is one of the most used models for examining the acceptance and use of Information Technology. The five perceived attributes of innovations (Relative advantage, Compatibility, Complexity, Observability, and Trialability) from the DOI model have been extensively investigated and found to explain about half of the variance in users' technology acceptance rates (Rogers 2003). This theory is regarded as a principal theoretical perspective on technology adoption, offering a conceptual framework for discussing adoption at a global level (Kapoor et al. 2013). Rogers (2003) has synthesized sixty years of innovation-adoption research in developing this theory. His model has been well received in the world of innovative solutions, and is one of the most used theories in the field of innovation diffusion (Kapoor et al. 2013). The concept of trialability is most suited in cases where a product/service is available for limited period for consumers to try, prior to making an adoption decision. Since open data is freely available for citizens to access and use as desired, without any concept of cost or usage bond/contract associated with it, this attribute has been omitted from this study.

In addition to attributes from the DOI model, there is one another aspect that tends to become the topic of concern when discussing open data. The aspect of associated risk is a topic that open data experts deal with on a regular basis. The risk of data being analysed or interpreted incorrectly, and that of open data being used against the publisher (Dodds 2015). The Diffusion of Innovations (DOI) model has undergone a minor modification to suit the context of this study, and a component of risk has been introduced in this case to account for security concerns associated with the use of open data (Fig. 1). More justification on the inclusion of risk as an additional factor can be found within section 3.1.5 below.

The effects/influences of relative advantage, compatibility, complexity, observability, and risk will be individually measured across users' behavioral intentions (Fig. 1). These five characteristics are expected to significantly impact users' intentions towards the usage of open data platforms. The positive or negative correlations that will surface post the empirical evaluations will then be logically reasoned and analyzed for their significance in influencing users' intentions towards using open data.

\subsection{Hypotheses development}

As justified in the earlier section, the modified and extended DOI model will now be further discussed for its attributes and their probable effects on users' intention to use open data. The

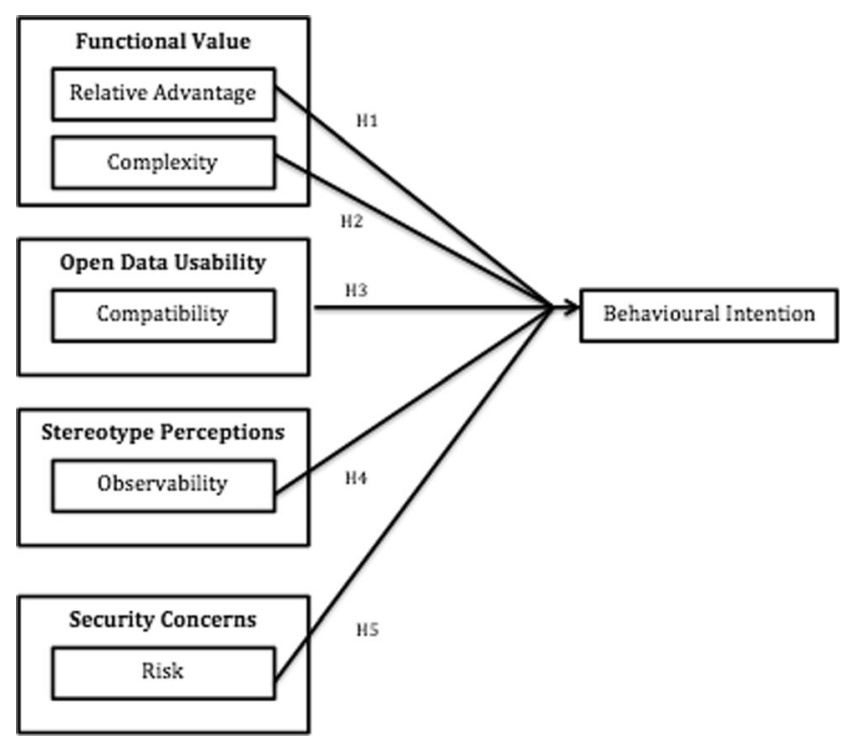

Fig. 1 Modified and extended DOI research model

four attributes from the DOI model were aimed at exploring different aspects spread across the functional value of using open data (relative advantage, complexity), its usability (compatibility), the stereotype perceptions associated with its use (observability), and the associated security concerns (risk). Hypotheses for each attribute have been individually discussed in the following parts of this section.

Behavioural intention, or use intention, or intention to use is one of the most frequently used attributes in the innovation related studies (Taylor and Todd 1995; Lu et al. 2008; Akturan and Tezcan 2010; Kapoor et al. 2013). As defined by Ajzen and Fishbein (1980), behavioural intention measures the likelihood of an individual being involved in a given behaviour. The behaviour of an individual, that is, their decision to accept or reject a technological innovation, is determined by their intention to perform that behavior, that is, their intention to use that technological innovation (Fishbein and Ajzen 1975). All hypotheses proposed in this study are aimed at examining the influences of the aforementioned five variables on behavioral intentions of the study's respondents. Since this study is interested in both adopters and non-adopters of open data, behavioural intention (as opposed to 'adoption') will be used as a dependent variable to account for both adopters and non-adopters.

\subsubsection{Relative advantage}

Relative advantage will help assess if the information available as open data is relatively better across multiple aspects in comparison to the same data that a citizen can access via other physical offices and platforms. In measuring the advantages of a new service, users tend to evaluate the pluses and minuses of using that service. Relative advantage is known to determine the ultimate rate of most innovation adoptions in the long run 
(Pannell et al. 2006). Citizens are likely to avoid paying attention to open data if they carry negative perceptions regarding its usefulness. Consistent with the theoretical principles underlying the DOI model, this study proposes a positive and significant effect of increased relative advantage on citizens' intentions to use open data.

H1: Relative advantage is positively related to citizens' behavioural intentions to use open data

\subsubsection{Complexity}

Users' knowhow of a service tends to dictate their perception of the level of effort involved in using that service. The less complex a service is to use/operate, the more easily it is accepted (Rogers 2003). The ease of using open data website will be evaluated from a perspective of optimizing user experience; the design of the interface, time required to look up for the desired information, understandability of different features/tabs offered within the website, and any other navigation complexities will be explored using this attribute (page layout, scrolling and paging, text appearances, links, search and so on). Existing research shows that difficulties in accessing open data and failure to update the same data on a regular basis by the government prevents organizations and people from relying on public sector open data (Kassen 2013). Presently, open data is mostly available in the raw data format. According to Martin (2014), the open data interfaces are not very user friendly, which fails to attract more number of users. Past research suggests that users tend to refrain from using a complex product/service despite being aware of its increased usefulness (Davis 1989). This creates a huge gap between the data content and its usability for the involved stakeholders and actor groups (Hunnius et al. 2014).

Since open data is mostly available in the raw format, it is not readily usable from a citizen's perspective. Much of this data varies in its content quality and often requires different layers of filtering at the legal, technical, and other levels before it becomes usable for citizens and businesses. As a resultant, most open data is dumped without any defined demarcations, making it difficult to be identified and traced by the interested stakeholders (Conradie and Choenni 2014). It is also important to note that ease of using or interpreting the available data is exclusive to individual users, and the skills/understanding required to interpret open data will be different for different users (Raman 2012; Martin 2014). Overall, efficient open data platforms and interfaces are expected to enhance citizens' ability to perform better. Based on the underlying argument, it is thus proposed in this study that easy to use services tend to positively influence consumer intentions.
H2: Reduced complexity is positively related to citizens' behavioural intentions to use open data.

\subsubsection{Compatibility}

In terms of compatibility, the website offering open data and the open data itself will be assessed for the type of information it offers to the citizens with respect to the type of information the citizens are interested in, or are expecting to access using such open data platforms. Rogers (2003) describes compatibility to be the degree with which the introduced innovation manifests itself as being consistent with users' past experiences, present values, and their future needs. It has often been recognized as an important predictor of consumers' use intentions (Putzer and Park 2010). Compatibility is proposed to measure the open data usability amongst citizens. This attribute has found its application across various innovation-adoption studies (Nakata and Weidner 2012; Lin 2011; Kapoor et al. 2013). According to Ilie et al. (2005), a higher level of compatibility prevailing over individual preferences and the technological innovation being considered is greatly preferred, since it enhances the probability of interpreting the innovation in question in a more familiar context.

In their research, Behkamal et al. (2014) found that public sector open data is sometimes mapped with incorrect values, questioning the credibility and quality of the data being made publicly available. At the same time, such data fails to cater to the information needs that an individual might be interested in, putting in question the compatibility of the data being opened to public. To measure how well the available information suffices with the information needs of a user, the compatibility of open data has been hypothesized as follows,

H3: Compatibility is positively related to citizens' behavioural intentions to use open data.

\subsubsection{Observability}

Monitoring of a system encourages peer discussions of that system, which collectively contributes towards achieving a better acceptance rate for that system (Rogers 2003). Rogers (2003) describes observability as the degree to which the outcomes of using an innovation become visible to others. Thus, the observability construct will be used in this study to help identify the awareness that the citizens have about the existence of such open data platforms that they can utilize for their benefit on a daily basis.

H4: Observability is positively related to citizens' behavioural intentions to use open data. 
Table 1 Respondent profile

\begin{tabular}{llll}
\hline Category & Values & Frequency & Percent \\
\hline Age & $18-24$ & 62 & 12.0 \\
& $25-34$ & 85 & 16.5 \\
& $35-44$ & 96 & 18.6 \\
& $45-54$ & 83 & 16.1 \\
& $55-64$ & 76 & 14.7 \\
& $65-74$ & 102 & 19.8 \\
Gender & Above 75 & 12 & 2.3 \\
& Total & 516 & 100.0 \\
& Male & 249 & 48.3 \\
& Female & 267 & 51.7 \\
\hline
\end{tabular}

\subsubsection{Risk}

A user's uncertainty about the quality of information being gathered can potentially lead to anxiety, which can come in the way of their adoption decision. The expected social or economic loss caused from using a new system constitutes perceived risk (Labay and Kinnear 1981; Rogers and Shoemaker 1971). In this context, the risk factor will be used to measure users' apprehensions of inputting personal information onto such websites, and also their confidence in using the information available on such websites. The quality of data published on the Internet is often questioned, and at the same time is also open to manipulation that in turn questions its reliability (Hand 2012). Reckman et al. (2011) point at researchers' apprehensions in sharing data publicly as that data is at the risk of being misused by other investigators.

Open data is open for people to use and build applications. In the process of doing so, there is huge potential for the data being wrongly recorded and presented. This would induce a risk of data being wrongly interpreted by the citizens who are relying on it to make important day-to-day decisions. At the same time, in its raw format, the data is not available to the public in a meaningful sense. As Roberts (2012) mentions, such raw data can be rightly interpreted by a selective and probably small set of technical experts, resulting in the risk of it again being misinterpreted by the larger proportion of citizens. They also point at the risk of digital divide and social inequality. Risk was thus deemed an important attribute from this study's perspective, and was hypothesized as follows to allow further examination in the UK context.

H5: Reduced risk is positively related to citizens' behavioral intentions to use open data.
Table 2 Respondent awareness of open data

\begin{tabular}{|c|c|c|c|}
\hline Category & Values & Frequency & Percent \\
\hline \multirow{4}{*}{$\begin{array}{l}\text { I am interested in finding out how different } \\
\text { government departments work }\end{array}$} & Yes & 352 & 68.2 \\
\hline & No & 77 & 14.9 \\
\hline & Not Sure & 87 & 16.9 \\
\hline & Total & 516 & 100.0 \\
\hline \multirow{4}{*}{$\begin{array}{l}\text { The availability of open data about public } \\
\text { services (E.g. education, health and social } \\
\text { care etc.) helps me take more informed decisions }\end{array}$} & Yes & 389 & 75.4 \\
\hline & No & 37 & 7.2 \\
\hline & Not Sure & 90 & 17.4 \\
\hline & Total & 516 & 100.0 \\
\hline \multirow[t]{4}{*}{ I have used open data websites before } & Yes & 155 & 30.0 \\
\hline & No & 279 & 54.1 \\
\hline & Not Sure & 82 & 15.9 \\
\hline & Total & 516 & 100.0 \\
\hline \multirow{4}{*}{$\begin{array}{l}\text { I am aware of the type of information that } \\
\text { open data websites offer }\end{array}$} & Yes & 206 & 39.9 \\
\hline & No & 207 & 40.1 \\
\hline & Don't know & 103 & 20.0 \\
\hline & Total & 516 & 100.0 \\
\hline \multirow{4}{*}{$\begin{array}{l}\text { Open data helps me understand how government } \\
\text { works, and how policies are made }\end{array}$} & Yes & 271 & 52.5 \\
\hline & No & 64 & 12.4 \\
\hline & Not Sure & 181 & 35.1 \\
\hline & Total & 516 & 100.0 \\
\hline \multirow{4}{*}{$\begin{array}{l}\text { I cannot relate to data on such open websites, } \\
\text { and would prefer more structured and } \\
\text { easily understandable information }\end{array}$} & Yes & 213 & 41.3 \\
\hline & No & 134 & 26.0 \\
\hline & Don't know & 169 & 32.8 \\
\hline & Total & 516 & 100.0 \\
\hline
\end{tabular}


Table 3 Citizen perspective of open data

\begin{tabular}{lll}
\hline & Frequency & Percent \\
\hline Lack of clarity in the availability of open data & 189 & 36.6 \\
Governments are opening up meaningful data. & 107 & 20.7 \\
Open data should offer insights into policy changes & 220 & 42.6 \\
Total & 516 & 100.0 \\
\hline
\end{tabular}

\section{Methodology}

This section is aimed at briefing the research design adopted for this study. The questionnaire design, data collection process, and data analysis have been exclusively discussed within this section.

\subsection{Questionnaire design and data collection}

A nationwide survey was undertaken to investigate citizens' perceptions and intentions to use open data in the UK. The data collection process was outsourced to a global sampling solutions provider, SSI. The company targeted UK based citizens from their database, who had prior knowledge of open data and open data systems by scripting the questionnaire onto an online survey tool. The survey target was set at 500 respondents, and the survey company took ten days to gather and return 516 responses, which were then used by the authors to conduct the intended statistical analysis. The questionnaire was divided into three parts. The first part of the questionnaire comprised of demographic questions, and other yes/no type of questions to gather basic information on the respondents' awareness of open data and open data platforms. The second part of the questionnaire required the respondents to choose one of three premade statements under the following categories: their perspective of open data, accountability in government functions, citizen participation (citizen involvement with the government in policy making and other decisions that affect citizens) and interaction, citizen exposure to government spending, and overall impact of open data.

Questions related to the adjusted DOI model with five constructs were recorded in the third part of the questionnaire. Each construct had three items/questions/statements, and the respondents were required to mark their agreement with the statement/question over a seven point Likert scale. The sevenpoint scales ranged from extremely disagree to extremely agree. While most questions were based on the items that have been previously used and tested in earlier research (Moore and Benbasat 1991; Karahanna et al. 1999; Tan and Teo 2000; Rijsdijk and Hultink 2003; Teo and Pok 2003; Shih and Fang 2004; Meuter et al. 2005; Mallat et al. 2008; Richardson 2009), these questions were considerably modified to suit the present context of open data and its impact on citizens and businesses.

Within the questionnaire, the concept of open data was explained along its availability and usability in a general context. In brief, its presence was recorded as governments making data publicly available across a selection of themes, such as local government finance, public spending, department-specific business plans, and other supporting geographical data to establish a level of transparency for facilitating informed decision making from the citizens' perspective. Examples of open data websites such as data.gov.uk, Geostore, Geomatics Group, MEDIN, and others were mentioned to understand respondents' awareness of open data and the platforms making such data publicly available.

\subsection{Pretesting the survey instrument}

The survey questionnaire was pretested with ten respondents, who were by profession - academicians, researchers, and citizens having general knowledge of open data. These test respondents were requested to fill questionnaires and report any possible errors that might have been introduced in the overall questionnaire design, the actual content, or any other difficulties hindering the understandability of the questions. Initially, a five point likert scale was employed, but the academicians and researchers suggested a seven-point scale, as seven point scales are known to assist in preventing the respondents from being too neutral in their responses; and also, the scales with more points are considered to be more reliable. The scaling was then changed to seven points on the likert scale. Each item in the questionnaire was initially numbered alongside the shorthand of the construct being measured. Academicians suggested the shorthand(s) be removed to prevent the construct from being interpreted by the respondents, which might influence their responses to a certain extent. The coding of the items was then changed to prevent respondents from
Table 4 Accountability in government functions

\begin{tabular}{lll}
\hline & Frequency & Percent \\
\hline Public knowledge empowers democracy & 99 & 19.2 \\
Accountability is not real, and corruption in the government continues & 210 & 40.7 \\
Without benefits of open data being promoted, accountability will only remain a goal & 207 & 40.1 \\
Total & 516 & 100.0 \\
\hline
\end{tabular}


Table 5 Citizen participation and interaction

\begin{tabular}{lll}
\hline & Frequency & Percent \\
\hline Public participation improves the quality of policy making & 211 & 40.9 \\
Government ensures citizens have tools/training to understand \& use open data & 80 & 15.5 \\
No clear means of providing citizen feedback or input on these open data & 225 & 43.6 \\
Total & 516 & 100.0 \\
\hline
\end{tabular}

picking any clue of the different constructs being measured (Ex: Previously compatibility was coded as COMPAT, and was later changed to $\mathrm{CP}$ ).

\section{Findings}

\subsection{Data analysis}

Data analysis was carried out using regression analysis to test the hypotheses proposed in this study. SPSS 20 was the statistical tool employed for undertaking regression analysis. The consistency of attributes in the model being analysed was measured using Cronbach's alpha. Coming to the desirable sample size, Stevens (1996) suggests that good statistical estimates and results can be achieved with a sample size of 300 and above. Literature also houses evidence, which vouch for a sample size of 300 to be a respectable number for achieving reliable results (Comrey and Lee 1992).

Summarized herein are the demographic statistics of respondents who undertook the survey on open data (Table 1). Overall, 516 valid responses were gathered. Respondents were fairly evenly distributed across different age groups. The highest number of respondents (102) belonged to the 65-74 years age group, followed closely by 96 people from the 35-44 years age group. About 85 respondents were between 25 and 34 years of age, and 83 respondents fell in the 45-54 years age group. The gender distribution was fairly even with 267 female respondents and slightly less male respondents (249 of 516).

Respondents were presented with a specific set of questions to gather their basic understanding of open data (Table 2). Of 516 respondents, 352 people were interested in finding out how different government department work, and 87 people were not sure if such piece of information interested them. Majority respondents (359 of 516) agreed that the availability of open data about public services (Example: education, health and social care, transport, etc.) helped them take more informed decisions. Only 155 respondents said they have used open data websites, with 279 respondents admitting to never having used them and 82 respondents not being sure, owing to their lack of knowledge of open data and different platforms offering such data. The proportion of respondents thinking they knew the type of information that the open data websites offer (206), and the proportion of respondents refusing any awareness about the information available of such sites (207) was almost the same. While more than half of the respondents (271) were of the opinion that open data helped them understand government functions and the idea behind different policies being made, the rest either disagreed (64), with most of them being unsure if open data offered any such insights at all (181). Given that most open data is available in the raw format, most respondents (213) found it difficult to interpret and understand, saying they would prefer more structured and easily understandable data.

Respondent views were also gathered on their perspectives of open data across the accountability in government functions, citizen participation and interaction, citizens' insight into government spending, and the overall impact of open data. The following set of tables contains statistics concerning these different aspects of open data.

When questioned about their perceptions of open data, most citizens (220 of 516) believed that open data should not only reveal transitions in policy decisions, but should also offer insights into why and how policy changes are made with evidence that trigger such changes (Table 3). Another major chunk of respondents (189 of 516) believed that Governments are opening up meaningful data (finance, housing etc.) to facilitate the fight against corruption. There were about 107 people standing by the fact that lack of clarity in the availability of open data is still concealing the full truth behind government operations, leaving opportunities for manipulation.
Table 6 Citizen exposure to Government spending

\begin{tabular}{lll}
\hline & Frequency & Percent \\
\hline Spending data has allowed people to see more of Government's accounts & 205 & 39.7 \\
Government's internal spending and management information can & 118 & 22.9 \\
$\quad$ be interrogated based on available open data & 193 & 37.4 \\
Government spending data is used to highlight government decisions & 516 & 100.0 \\
Total & & \\
\hline
\end{tabular}


Table 7 Overall Impact

\begin{tabular}{lll}
\hline & Frequency & Percent \\
\hline $\begin{array}{l}\text { By opening up data, government is driving the creation of } \\
\text { innovative business \& services }\end{array}$ & 106 & 20.5 \\
Making data available supports the shaping of society & 188 & 36.4 \\
Transparency in data is more than open access & 222 & 43.0 \\
Total & 516 & 100.0 \\
\hline
\end{tabular}

When asked for their opinions on the accountability in government functions, majority respondents (210 of 516) thought accountability is not real, and corruption in the government continues to exist (Table 4). Running close to this opinion, 207 people of the 516 surveyed believed that without motivated citizens and journalists promoting the benefits of open data, accountability would only remain a goal. There was also a small set of people (99 of 516) who went along the fact that nearly every time one finds accountability within democracy, there is public knowledge empowering it.

In finding out about their participation and interaction with open data, most respondents (225 of 516) complained that there are no clear means of providing citizen feedback or input on these open data platforms that effectively impact future policy decisions (Table 5). On the other hand, 211 respondents believed their participation will and does improve the quality of policymaking, bringing greater accountability and transparency that helps deepen democracy. There were only 80 respondents who thought the government is taking enough measures to ensure that citizens have the tools/training to understand and make use of the information revealed on open data websites.

In investigating how much insight citizens have on government spending, 205 of 516 respondents were happy about the fact that the release of spending data has allowed them to see more of Government's accounts to establish value for money on behalf of the taxpayer (Table 6). The next big chunk of respondents (193 of 516) thought journalists and campaigning organizations were mostly using the available government spending data to highlight government decisions and support associated campaigns. About 118 respondents believed that government's internal spending and management information could be interrogated based on available open data.

Table 8 Reliability test

\begin{tabular}{lllll}
\hline Constructs & Sample & Items & Cronbach's $\alpha$ & Reliability \\
\hline Relative Advantage & 516 & 3 & .812 & High \\
Compatibility & 516 & 2 & .515 & Moderate \\
Complexity & 516 & 2 & .359 & Low \\
Observability & 516 & 2 & .643 & Moderate \\
Risk & 516 & 2 & .666 & Moderate \\
Behavioral Intention & 516 & 2 & .704 & High \\
\hline
\end{tabular}

In gaining views about the overall impact of open data, most respondents (222 of 516) were found to believe that transparency in data is beyond just open access, and more about sharing and reusing data that can be visualized and analysed to question the present state of affairs (Table 7). The next big set of respondents (188 of 216) believed that making government data available supports the shaping of society. Lastly, about 106 respondents thought that by opening up data, government is driving the creation of innovative businesses and services, capable of delivering social and commercial value.

\subsection{Construct reliability}

While using survey instruments, it is always a good practice to ensure that the instrument in use will consistently produce reliable responses in all possibilities of the questions in the instrument being replaced with analogous questions (Santos 1999). Cronbach's alpha is one such reliability statistic that provides a measure of the internal consistency or an average correlation among the items involved in the instrument to estimate its reliability (Santos 1999). To begin with, all five constructs had three items each, but during the reliability test it was revealed that deleting certain items could increase the reliability of some of the constructs. In the interest of achieving a well-fitting model, some constructs underwent item deletion to achieve stronger reliability (higher Cronbach's alpha value). A reliability test was conducted on the survey instrument for this study (Table 8). As cited in Dwivedi (2005), there are four points for Cronbach's alpha representative of reliability (i) 0.90 and above indicating excellent reliability (ii) $0.70-0.90$ for high reliability (iii) $0.50-0.70$ reflecting moderate reliability, and (iv) 0.50 and below for low reliability.

Of the six attributes being used in the model, behavioural intention and relative advantage showed high reliabilities. Except complexity, the remaining three attributes showed moderate reliabilities. Owing to its very poor reliability and

Table 9 Model summary

Model R R Square Adjusted R Square Std. Error of the Estimate

\begin{tabular}{lllll}
\hline & $.708^{\mathrm{a}}$ & .501 & .497 & .81138
\end{tabular}

${ }^{a}$ Predictors: (Constant), Compatibility, Risk, Relative Advantage, Observability. 
Table 10 ANOVA $^{\mathrm{a}}$

\begin{tabular}{lllllll}
\hline Model & Sum of Squares & df & Mean Square & F & Sig. \\
\hline 1 & Regression & 337.579 & 4 & 84.395 & 128.192 & $.000^{\mathrm{b}}$ \\
Residual & 336.415 & 511 & .658 & & \\
Total & 673.994 & 515 & & & \\
\hline
\end{tabular}

${ }^{a}$ Dependent Variable: Behavioral Intention.

${ }^{\mathrm{b}}$ Predictors: (Constant), Compatibility, Risk, Relative Advantage, Observability.

in the interest of satisfactory model performance, it was decided that complexity $(\alpha=.359)$ should be eliminated from the model. Therefore, the effects of relative advantage, compatibility, observability, and risk on behavioural intention will be examined using regression analysis.

\subsection{Regression analysis}

Linear regression analysis provides an estimate of the linear equation coefficients, concerning one or more independent variables that result in the best prediction of the dependent variable value (Draper and Smith 1998). Regression analysis was thus carried out for the 516 gathered cases in accordance with the proposed conceptual model for this study. In this model, four independent variables - relative advantage, compatibility, observability, and risk were examined for their influences on one dependent variable, behavioural intention. The results from this regression run have been captured in tables 9, 10 and 11. The analysis divulges a momentous model: $(\mathrm{F}(4,516)=128.192, p=.000)$ with an adjusted $\mathrm{R}$ square value of 0.497 . As seen in Table 11, the variables, relative advantage (Beta $=.382, p=.000)$, compatibility $($ Beta $=.294, p=.000)$, and observability (Beta $=.186, p=.000)$ were captured as the significant predictor variables, whereas, risk (Beta $=-.059, p=.070)$ turned out have no significant effect on citizens' intentions.

It is clear from linear regression analysis that predictors of the modified and extended DOI model accounted for $49.7 \%$ variability (Table 9) of behavioural intention to use open data platforms. Relative advantage $($ Beta $=.382, p=.000)$ and compatibility (Beta $=.294, p=.000)$ are the strongest predictors of citizens' intentions to use open data (Table 11).

The functional value of open data was measured using relative advantage (Fig. 2). In rating the relative advantage of open data, about $36 \%$ slightly agreed that knowledge of government, available in the form of open data, creates accountability (RA1). While $26 \%$ respondents were neutral about the idea, $23 \%$ showed agreement, and only $8 \%$ were in extreme agreement. While $36 \%$ people were neutral about the idea that open data offered flexibility in their daily decision-making, $53 \%$ respondents showed agreement (RA2). About $65 \%$ people believed that open data helped them better understand the governmental affairs, directly affecting them on a daily basis (RA3, Table 12).

About $33 \%$ respondents were neutral about the statement I believe, open data will fit my needs to access information affecting my lifestyle, such as statistics on housing, crime rates, accidents, flood maps, food hygiene, transport etc., with only $29 \%$ people agreeing with it (CT1). There were only $11.6 \%$ respondents who believed that using open data websites will not be compatible with their information needs (CT2). In addition, only $18 \%$ people thought that not all their devices (mobiles, tablets, desktops, laptops $\&$ others) were compatible with open data websites (CT3, Table 13).

About $40 \%$ respondents agreed that organizations worldwide are working towards openness and transparency in governments, and more involvement of citizens in political decisions (O1). Not many respondents $(31 \%)$ witnessed other people make well informed decisions on the basis of open data $(\mathrm{O} 2)$. About $72 \%$ people agreed that individuals using open data were not visible in their social circles (O3, Table 14).

About $42 \%$ respondents were only neutral about the statement that the information available on open data websites is reliable and accurate, with about $25 \%$ respondents disagreeing to it (R1). About half of the respondent sample was concerned about making a wrong decision based on the available data (R2). While $36 \%$ respondents remained neutral, around $42 \%$ agreed that transparent data on such open data websites clashes with ethics of privacy, leaks, and is a threat to the overall national security (R3, Table 15).

Table 11 Coefficients $^{\mathrm{a}}$

\begin{tabular}{lllllll}
\hline Model & \multicolumn{2}{l}{ Unstandardized Coefficients } & & Standardized Coefficients & $\mathrm{t}$ & Sig. \\
\cline { 2 - 3 } & $\mathrm{B}$ & Std. Error & & Beta & & \\
\hline Constant) & .224 & .232 & & .965 & .335 \\
Relative Advantage & .464 & .047 & .382 & 9.966 & .000 \\
Risk & -.062 & .034 & -.059 & -1.818 & .070 \\
Observability & .186 & .040 & .186 & 4.667 & .000 \\
Compatibility & .355 & .049 & .294 & 7.259 & .000 \\
\hline
\end{tabular}

${ }^{a}$ Dependent Variable: Behavioral Intention. 


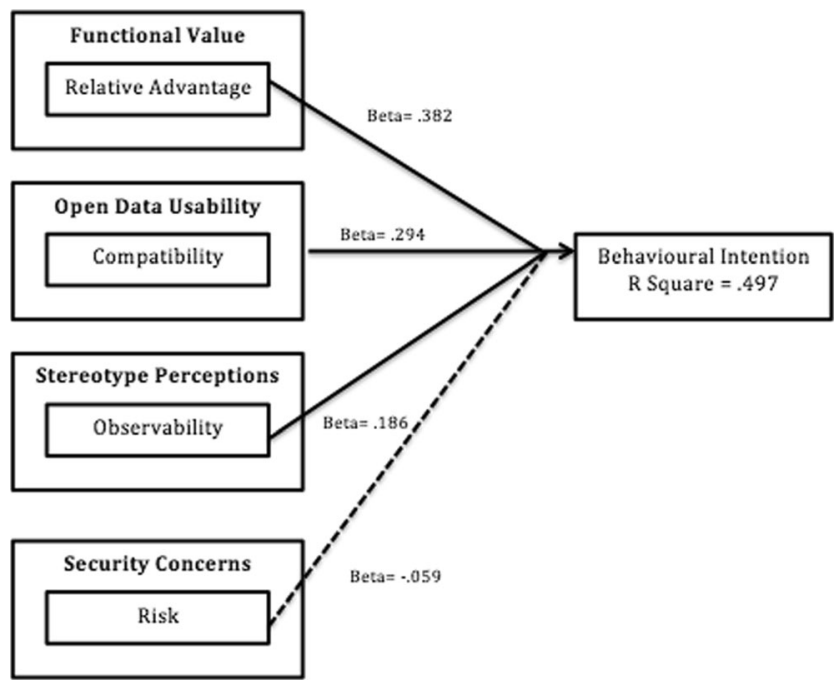

Fig. 2 Validated Research Model

In rating the responses for items related to behavioral intentions, about $60 \%$ respondents thought that transparency is a central issue for public opinion in democracies, worldwide, which enhances their interest in using open data (BI1). While $27 \%$ people were neutral about it, about $62 \%$ agreed that they support transparency and are reassured by the presence of such mechanisms, but their personal willingness to use open data is not high (BI2). However, there were about $47 \%$ respondents saying that the likelihood of them using open data is very high (BI3, Table 16).

\section{Discussions}

Overall, it is apparent that the citizens are not convinced about the level of transparency of open data and the government functions (Table 4, section 5.1). While the entire idea of accountability is questionable, people do believe that the corruption in the government functions is persisting, if not rising. There is also a general consensus on not being well informed about the benefits of having access to open data. People need to be educated about the existence and usefulness of such government data that not only presents them with an opportunity to use such data in their day-to-day decisions, but also gives them a free hand in being involved in different policy making processes. Despite having the willingness to contribute and interact with the government via open data platforms for better policymaking, not many people think they have the means to communicate with the government (Table 5, section 5.1). Most of them find it hard to identify and effectively use the tools/training that the government might be offering to increase citizen participation and their understandability of the usefulness of open data.

Behavioural intention is perceived as an instinctive probability that a user relates directly with the possibility of a particular behavioural option being chosen (Chiu 2003). Many models of innovation adoption and diffusion recognize behavioural intention as the best predictor of human behaviour (Lee and Rao 2009; Ozaki 2011). Many studies of the past have acknowledged the importance of relative advantage in consumers forming favourable use intentions towards a given innovation. This attribute has marked its presence across varied innovation-types (Mallat et al. 2006, 2008; Schierz et al. 2010; Bae and Chang 2012; Jung et al. 2009; Chou et al. 2012; Tapaninen et al. 2009). Based on the revelations and evidences from many such studies, it was expected that relative advantage would have a significant impact on the behavioural intentions of the users of open data. Completely in line with the made proposition, H1, and the findings of the past studies, this study saw a significant influence of relative advantage on behavioural intentions of the consumers. This shows that users have formed positive ideas about the probable usefulness of open data.

Reinstating the previously made comments about relative advantage, joining the list is compatibility, with these two factors being the most used attributes, and more often being concluded as the prominent most contributing factors in the adoption of internet-based technologies (Al-Jabri and Sohail 2012). Compatibility may refer to compatibility with existing norms and values of the potential adopters, or may be a representative of its congruence with the existing practices of those potential adopters (Tornatzky and Klein 1982). Past studies have been vouching for more compatible innovations capable of enhancing users' competencies and determination for using those and those-like innovations (Chau and Lai 2003; Lin 2011). With hypothesis, H2 turning out significant, it can be concluded that more compatible open data is expected to positively influence citizens' usage intentions. It can thus be concluded that citizens prefer familiar platforms and easily accessible open data that they can put to use in their day to day decision making, or in just keeping themselves informed of government functions and different policy changes affecting them.
Table 12 Frequencies for relative advantage

\begin{tabular}{llllllll}
\hline $\begin{array}{l}\text { Relative } \\
\text { advantage }\end{array}$ & $\begin{array}{l}\text { Extremely } \\
\text { disagree }\end{array}$ & Disagree & $\begin{array}{l}\text { Slightly } \\
\text { disagree }\end{array}$ & Neutral & $\begin{array}{l}\text { Slightly } \\
\text { agree }\end{array}$ & Agree & $\begin{array}{l}\text { Extremely } \\
\text { agree }\end{array}$ \\
\hline RA1 & 3 & 3 & 22 & 138 & 189 & 119 & 42 \\
RA2 & 3 & 12 & 38 & 185 & 146 & 104 & 28 \\
RA3 & 2 & 4 & 41 & 128 & 175 & 132 & 34 \\
\hline
\end{tabular}


Table 13 Frequencies for compatibility

\begin{tabular}{lllllrrr}
\hline Compatibility & Extremely disagree & Disagree & Slightly disagree & Neutral & Slightly agree & Agree & Extremely agree \\
\hline CT1 & 2 & 16 & 43 & 172 & 136 & 112 & 35 \\
CT2 & 8 & 57 & 99 & 203 & 89 & 43 & 17 \\
CT3 & 14 & 30 & 56 & 207 & 117 & 67 & 25 \\
\hline
\end{tabular}

Observability is acknowledged to improve with increased earlier adoption in the users' social circles, with the impact to be produced by this being attributed to the so-called bandwagon effect (Abrahamson and Rosenkopf 1997). In measuring the stereotype perceptions, hypothesis H4 was supported by the empirical data to show positive and significant effects of observability on users' intentions to use open data. According to Meuter et al. (2005), observability assists in showing positive outputs, which in turn motivates potential adopters to receive that innovative product/service's rewards. In this case, the respondents agreed that they have had the opportunity, mostly limited, to observe others use and talk about open data, which has managed to leave a positive mark in their minds about the usability of open data.

Hypothesis, H5, was seen behaving contrary to the postulated relationship, with risk being declared an unimportant predictor of intention for this study. This attribute measured the security concerns of the users in using Government released data. The literature is rich with findings from studies that show a significant influence of risk on users' adoption intentions (Schaupp and Carter 2010); for instance - Taylor and Strutton (2010) in their meta-analysis on Internet consumer behaviours found that perceived risk had a strong negative effect on the behavioural intentions. However, in line with our contrasting findings, Claudia et al. (1994) make a point in their study stating that despite the existence of perceived risks, some users choose to overcome fear and adopt/use the product/service. They also suggest that perceptions of risk diminish over time. The same can be argued with this study. People are well acquainted with the use of ICT. The generations are well exposed to the idea of using the content available on the web at their discretion. Increased use of social media and content published online has the citizens well exposed to the fact that there can be some misleading/incorrect information published even across most trusted sites. Individuals have matured in their usage of online content, and probably understand the extent to which they can allow themselves to rely on open data in their daily decisions; this must have rendered risk a non-significant attribute for most respondents.

Most open data released by the government is available in the raw format, which restricts its understandability by all people. Essentially, this data is mostly usable by experts with some technical knowledge to interpret and develop applications, which can be of use to the general public. Since this questionnaire was circulated across a random sample of population, there is a very high probability that these respondents found it difficult to relate with the data, mostly available in the form of statistics to apply in their daily lives. Thus, there are chances that most respondents suffered limited understandability of the raw data, which might have got them disinterested in open data with them conveniently overlooking the possible risks involved with the use of such data. These arguments suggest that respondents have overcome the idea of risk involved in using data published on the web, hence the non-significance of risk on their overall behavioral intentions.

Theoretical and practical implications From a theoretical perspective, the paper has made significant contributions. Given the significance of open data as a local and central Government imperative, the conceptualization of potential usefulness of open data from citizens' perspective offers policy makers and researchers new insights in moving forward in the field of public sector open data. Moreover, there is no evidence in the literature on the existence of a survey instrument or conceptual model assessing citizens' intentions towards the use of public sector open data, making this a normative reference source to test citizens' perceptions of public sector open data.

From a practical perspective, the authors have offered a snapshot of citizens' perceptions of the usability of open data. The findings in this study offer UK digital government policy makers and practitioners some important insights in relation to what citizens think presently about open data in the UK.

Table 14 Frequencies for observability

\begin{tabular}{lllllrrr}
\hline Observability & Extremely disagree & Disagree & Slightly disagree & Neutral & Slightly agree & Agree & Extremely agree \\
\hline O1 & 12 & 23 & 76 & 200 & 115 & 72 & 18 \\
O2 & 21 & 62 & 71 & 201 & 78 & 57 & 26 \\
O3 & 10 & 14 & 34 & 179 & 123 & 113 & 43 \\
\hline
\end{tabular}


Table 15 Frequencies for risk

\begin{tabular}{llllllll}
\hline Risk & Extremely Disagree & Disagree & Slightly Disagree & Neutral & Slightly Agree & Agree & Extremely Agree \\
\hline R1 & 4 & 28 & 62 & 216 & 117 & 65 & 24 \\
R2 & 5 & 21 & 45 & 187 & 153 & 77 & 28 \\
R3 & 22 & 41 & 92 & 186 & 108 & 45 & 22 \\
\hline
\end{tabular}

Notwithstanding, these conclusions can contribute towards a deeper, more international study, where their significance can be evaluated for scalability. The findings suggest that UK citizens are only likely to use open data if there is clear evidence of an advantage in doing so, relative to current practice. The current practice of promoting open data as a means to improve transparency in government seems to be working, especially when it comes to citizens' perception on risk regarding the potential use of open data, as most citizens seem to have no concerns regarding the use of open data. As such, the government needs to ensure that useful data that is open to public offers clear benefits to the citizens to entice potential users.

\section{Conclusions, limitations and future research directions}

Review of both the normative literature and secondary information sources suggest that public sector open data are intended to offer the business community and citizens a multitude of benefits. However, a careful analysis of publically available open data resources in the UK, such as the data.gov.uk website and other local government websites that offer access to open data, reveal that this domain is still in its nascent stage. As a result, there is a disconnection between potential and realistic impact of open data.

Available open data is not linked/well structured. Consequently, the data cannot easily be interrogated using even rudimentary analytics to structure it [data] that can then form the basis of information. It is this information that empowers the user to draw meaningful conclusions and therefore contribute to the policy making process. The rawness of open data appears to discourage extrapolation of data clusters to construct meaningful information. In its current form, citizens are unable to use the data for any meaningful purpose relating to their life events or decisions. However, there is no doubt that public sector open data in the UK offers the business community and local government agencies several opportunities for improved decision-making, service optimization and cost savings. Previously closed or limited by distribution, data that were stored in internal systems and too complex to understand by front line workers and managers, are now available in a more simplified format. In part, facilitated by better data analytics now allows better decision making at both central and local government levels. These observations are supported through evidence collected in this study, which surveys over 500 citizens.

The genesis extrapolated from the analysis conducted within this paper concludes that the empirical findings suggest that relative advantage was the strongest predictor of behavioural intention relating to citizens' perception of open data and its potential use. Secondly, relative advantage, compatibility, and observability positively and significantly predicted behavioural intentions of citizens to use open data. Thirdly, and interestingly, risk had no significant influence on citizens' use intentions, as respondents clearly did not believe that there was any significant risk associated with open data, perhaps mitigated by the benefits of data transparency. Implicitly, this may suggest that most citizens have no concerns about trusting public sector open data.

We acknowledge that the findings in this paper have to be interpreted in the light of several limitations. In particular, the low reliability of complexity in our survey sample meant that this construct had to be excluded from the analysis, resulting in no revelations on how citizens perceived this component in relation to open data. In addition, due to the embryonic nature of public sector open data, as well as its limited relevance and benefits to citizens at present, the attributes were only examined for their influence on intention and not on adoption. Nevertheless, the opportunity afforded to the citizen is now considered far reaching and empowering, with adoption ripe for examined in future studies. Notwithstanding, another limitation is recognized by the fact that although care was taken to gather data from citizens who have knowledge of open data,

Table 16 Frequencies for behavioral intention

\begin{tabular}{lccccccc}
\hline Behavioral Intention & Extremely Disagree & Disagree & Slightly Disagree & Neutral & Slightly Agree & Agree & Extremely Agree \\
\hline BI1 & 3 & 15 & 15 & 180 & 150 & 114 & 39 \\
BI2 & 2 & 9 & 36 & 142 & 163 & 122 & 42 \\
BI3 & 48 & 67 & 146 & 123 & 88 & 30 & \\
\hline
\end{tabular}


majority respondents have not used open data (see Table 2). Future research will be aimed at a more focussed sample, where all respondents have first-hand experience of using open data to arrive at specific outcomes on the advantages of open data from a citizen's perspective. However, this in itself also raises the deeper social question around the public's knowledge around open data availability and their ability to influence change. Also, this study used regression analysis to analyse the individual effects of the chosen constructs; future study will be focused on structural equation modelling where AMOS will be employed to produce extensive results on the behaviour of different factors, affecting the acceptance of open data. While only five attributes (DOI attributes) were evaluated within this study, the aim is to study the relevance of other attributes (such as visibility, result demonstrability, image and so on) to open data, and their consequent effects on citizens' intentions to use open data. Lastly, the authors also intend to examine how open data can be used to improve the quality of life whilst encouraging the implementation of innovative solutions and services.

Open Access This article is distributed under the terms of the Creative Commons Attribution 4.0 International License (http:// creativecommons.org/licenses/by/4.0/), which permits unrestricted use, distribution, and reproduction in any medium, provided you give appropriate credit to the original author(s) and the source, provide a link to the Creative Commons license, and indicate if changes were made.

\section{References}

Abrahamson, E., \& Rosenkopf, L. (1997). Social network effects on the extent of innovation diffusion: A Computer Simulation. Organization Science, 8(3), 289-309.

Ajzen, I. and Fishbein, M. (1980). Understanding attitudes and predicting social behavior. Engle-wood-Cliffs, NJ: Prentice-Hall.

Akturan, U. L. U. N. and Tezcan, N. U. R. A. Y. (2010). The Effects of Innovation Characteristics on Mobile Banking Adoption. In proceedings of the 10th Global Conference on Business and Economics, Rome.

Al-Jabri, I. M., \& Sohail, M. S. (2012). Mobile Banking Adoption: Application of Diffusion of Innovation Theory. Journal of Electronic Commerce Research., 13(4), 379-391.

Arzberger, P., Schroeder, P., Beaulieu, A., Bowker, G., Casey, K., Laaksonen, L., \& Wouters, P. (2004). An international framework to promote access to data. Science, 303(5665), 1777-1778.

Bae, Y., \& Chang, H. (2012). Adoption of Smart TVs: A Bayesian Network Approach. Industrial Management and Data Systems., $112(6), 891-910$.

Behkamal, B., Kahani, M., Bagheri, E., \& Jeremic, Z. (2014). A metricsdriven approach for quality assessment of linked open data. Journal of Theoretical and Applied Electronic Commerce Research, 9(3), 64-79.

Bertot, J. C., Jaeger, P. T., \& Grimes, J. M. (2010). Using ICTs to create a culture of transparency: e-government and social media as openness and anti-corruption tools for societies. Government Information Quarterly, 27(3), 264-271.

Bertot, J. C., McDermott, P., \& Smith, T. (2012). Measurement of open government: metrics and process. In Paper presented at the 45th Hawaii International Conference on System Sciences. Hawaii: U.S.A.
Borzacchiello, M. T., \& Craglia, M. (2012). The impact on innovation of open access to spatial environmental information: a research strategy. International Journal of Technology Management, 60(1-2), 114-129. doi:10.1504/ijtm.2012.049109.

Braunschweig, K., Eberius, J., Thiele, M. and Lehner, W. (2012). The State of Open Data Limits of Current Open Data Platforms.

Carter, L., \& Weerakkody, V. (2008). E-government adoption: a cultural comparison. Information Systems Frontiers, 10(4), 473-482.

Castellanos, M., Daniel, F., Garrigós, I. and Mazón, J. N. (2013). Business intelligence and the web. Information Systems Frontiers, 15(3), 307

Chau, P. Y., \& Lai, V. S. (2003). An empirical investigation of the determinants of user acceptance of internet banking. Journal of Organizational Computing and Electronic Commerce, 13(2), 123-145.

Chiu, R. K. (2003). Ethical judgment and whistleblowing intention: examining the moderating role of locus of control. Journal of Business Ethics, 43(1-2), 65-74.

Choenni, S., van Dijk, J., \& Leeuw, F. (2010). Preserving privacy whilst integrating data: Applied to criminal justice. Information Polity, 15, 125-138.

Chou, C. J., Chen, K. S. and Wang, Y. Y. (2012). Green practices in the restaurant industry from an innovation adoption perspective: evidence from Taiwan. International Journal of Hospitality Management 31(3), 703-711.

Claudia, I., Alexandra, P., \& Ionut, M. O. (1994). The Influence of Perceived Risk on Consumers' Intention to Buy Online: A MetaAnalysis of Empirical Results. Journal of Information Systems and Operations Management., 6(1), 162-174.

Comrey, A. L. and Lee, H. B. (1992). A first course in factor analysis. 2nd Edition. Hillsdale NJ: Erlbaum.

Conradie, P., \& Choenni, S. (2014). On the barriers for local government releasing open data. Government Information Quarterly, 31, S10-S17.

Cranefield, J., Robertson, O. and Oliver, G. (2014), Value In The Mash: Exploring The Benefits, Barriers And Enablers Of Open Data Apps, Proceedings of the European Conference on Information Systems (ECIS) 2014, Tel Aviv, Israel, June 9-11, 2014, ISBN 978-09915567-0-0

Data.gov.uk, (2015). About | data.gov.uk. [Online] Available at: http://data.gov.uk/about [Accessed 13 Jun. 2015].

Davis, F. D. (1989). Perceived usefulness, perceived ease of use, and user acceptance of information technology. MIS Quarterly, 13(3), 319-340.

Dodds, L. (2015). Managing risks when publishing open data. Available at http://blog.ldodds.com/2015/11/15/managing-risks-whenpublishing-open-data/. Accessed on: 16 Jan 2016.

Draper, N.R. and Smith, H. (1998). Applied regression analysis. 3rd edition. New York, NY: Wiley-Interscience

Dwivedi, Y.K. (2005). Investigating Adoption, Usage and Impact of Broadband: UK Households. Unpublished PhD Thesis, DISC, Brunel University.

Dwivedi, Y. K., Wastell, D., Laumer, S., Henriksen, H. Z., Myers, M. D., Bunker, D., Elbanna, A., Ravishankar, M. N., \& Srivastava, S. C. (2015). 'research on information systems failures and successes: status update and future directions'. Information Systems Frontiers, 17(1), 143-157.

Fang, X., \& Holsapple, C. W. (2007). An empirical study of web site navigation structures' impacts on web site usability. Decision Support Systems, 43(2), 476-491.

Fishbein, M. and Ajzen, I. (1975). Belief, Attitude, intention, and behavior: An introduction to theory and research. Reading, Mass: Addison-Wesley.

Hand, D. (2012). Open data is a force for good, but not without risks. Available at: https://www.theguardian.com/society/2012/jul/10 /open-data-force-for-good-risks. Accessed 6 Nov 2015. 
Hunnius, S., Krieger, B., \& Schuppan, T. (2014). Providing, guarding, shielding: Open Government Data in Spain and Germany. Paper presented at the European Group for Public Administration Annual Conference. Germany: Speyer.

Ilie, V., Van Slyke, C., Green, G., \& Lou, H. (2005). Gender differences in perceptions and use of communication technologies: a diffusion of innovation approach. Information Resources Management Journal, 18(3), 13-31.

Irani, Z., Sharif, A. M., Kamal, M., \& Love, P. E. D. (2014). Visualising a Knowledge Mapping of Information Systems Evaluation. Expert Systems with Applications, 41(1), 105-125.

Janssen, M., Charalabidis, Y., \& Zuiderwijk, A. (2012). Benefits, adoption barriers and myths of open data and open government. Information Systems Management, 29(4), 258-268.

Jung, Y., Perez-Mira, B., \& Wiley-Patton, S. (2009). Consumer adoption of mobile TV: examining psychological flow and media content. Computers in Human Behavior, 25(1), 123-129.

Kapoor, K., Dwivedi, Y. K., \& Williams, M. D. (2013). Role of Innovation Attributes in Explaining the Adoption Intention for the Interbank Mobile Payment Service in an Indian Context. In Grand Successes and Failures in IT Public and Private Sectors (pp. 203220). Berlin Heidelberg: Springer.

Karahanna, E., Straub, D. W., \& Chervany, N. L. (1999). Information technology adoption across time: a cross-sectional comparison of preadoption and post-adoption beliefs. MIS Quarterly, 23(2), 183-213.

Kassen, M. (2013). A promising phenomenon of open data: A case study of the Chicago open data project. Government Information Quarterly, 30(4), 508-513.

Labay, D. G. and Kinnear, T. C. (1981), 'exploring the consumer decision process in the adoption of solar energy systems', Journal of Consumer Research, 8(3), 271-278.

Lee, J., \& Rao, H. R. (2009). Task complexity and different decision criteria for online service acceptance: a comparison of two egovernment compliance service domains. Decision Support Systems, 47(4), 424-435. doi:10.1016/j.dss.2009.04.009.

Lin, H. F. (2011). An empirical investigation of mobile banking adoption: the effect of innovation-attributes and knowledge-based trust. International Journal of Information Management, 31(3), 252-260.

Lu, J., Liu, C., Yu, C.-S., \& Wang, K. (2008). Determinants of Accepting Wireless Mobile Data Services in China. Information Management, 45(1), 52-64.

Mallat, N., Rossi, M., Tuunainen, V.K., and Oorni, A. (2006). The Impact of Use Situation and Mobility on the Acceptance of Mobile Ticketing Services, In Proceedings of the 39th Hawaii International Conference on System Sciences.

Mallat, N., Rossi, M., Tuunainen, V. K., \& Oorni, A. (2008). An empirical investigation of mobile ticketing service adoption in public transportation. Personal and Ubiquitous Computing, 12(1), 57-65.

Martin, C. (2014). Barriers to the open government data agenda: taking a multi-level perspective. Polymer International, 6(3), 217-240. doi:10.1002/1944-2866.

Martín, A. S., de Rosario, A. H., Pérez, C. C. (2015) Open Government Data: A european Perspective. Information and Communication Technologies in Public Administration: Innovations from Developed Countries, 195

McDermott, P. (2010). Building open government. Government Information Quarterly, 27(4), 401-413.

Meuter, M. L., Bitner, M. J., Ostrom, A. L., \& Brown, S. W. (2005). Choosing among Alternative Service Delivery Modes: An Investigation of Customer Trial of Self-Service Technologies. The Journal of Marketing., 69(2), 61-83.

Moore, G. C., \& Benbasat, I. (1991). Development of an instrument to measure the perceptions of adopting an information technology innovation. Information Systems Research, 2(3), 192-222.

Nakata, C., \& Weidner, K. (2012). Enhancing new product adoption at the base of the pyramid: A Contextualized Model. Journal of Product Innovation Management, 29(1), 21-32.
Osman, I. H., Anouze, A. L., Irani, Z., Al-Ayoubi, B., Lee, H., Balc1, A., Medeni, T. D., \& Weerakkody, V. (2014). COBRA framework to evaluate egovernment services: a citizen-centric perspective. Government Information Quarterly, 31(1), 243-256.

Ozaki, R. (2011), Adopting sustainable innovation: what makes consumers sign up to green electricity?. Business Strategy and the Environment, 20(1), 1-17.

Pannell, D. J., Marshall, G. R., Barr, N., Curtis, A., Vanclay, F., \& Wilkinson, R. (2006). 'understanding and promoting adoption of conservation practices by rural landholders'. Australian Journal of Experimental Agriculture, 46(11), 1407-1424.

Putzer, G. J., \& Park, Y. (2010). The effects of innovation factors on smartphone adoption among nurses in community hospitals. Perspectives in Health Information Management, 7(1), 1-8.

Raman, B. (2012). The rhetoric and reality of transparency: transparent information, opaque city spaces and the empowerment question. The Journal of Community Informatics, 8(2) [n.p.].

Rana, NP, Dwivedi, YK, Lal, B., Williams, MD and Clement, M (2015) Citizens' adoption of an electronic government system: Towards a unified view, forthcoming in information systems Frontiers, available at http://ink.springer.com/article/10.1007/s10796-015-9613-y

Reckman, H., Orkin, J., \& Roy, D. (2011) Extracting aspects of determiner meaning from dialogue in a virtual world environment. In proceedings of the Ninth International Conference on Computational Semantics (pp. 245-254). Oxford, UK: Association for Computational Linguistics.

Richardson, J.W. (2009). Technology adoption in Cambodia: measuring factors impacting adoption rates. Journal of International Development 23(5) 697-710.

Rijsdijk, S. A., \& Hultink, E. J. (2003). Honey, Have you seen our hamster? Consumer evaluations of autonomous domestic products. Journal of Product Innovation Management, 20(3), 204-216.

Roberts, T. (2012). The Problem with Open Data. Available at: http://www.computerweekly.com/opinion/The-problem-withOpen-Data. Accessed on: 6 Nov 2015.

Rogers, E. M. (2003). Diffusion of Innovations (5th ed.). New York: The Free Press.

Rogers, E. M., \& Shoemaker, F. F. (1971). Communication of innovations. New York: Free Press.

Rose, J., Persson, J., Heeager, L., \& Irani, Z. (2015). Managing eGovernment: value positions and relationships. Information Systems Journal, 25(5), 531-571.

Santos, J.R.A. (1999). Cronbach's Alpha: A Tool for Assessing the Reliability of Scales Journal of Extension. 37(2) Available from: http://www.joe.org/joe/1999april/tt3.html. Accessed date: 30-08-2010

Schaupp, L. C., \& Carter, L. (2010). The impact of trust, Risk and Optimism Bias on E-File Adoption. Information Systems Frontiers, 12(3), 299-309.

Schierz, P. G., Oliver Schilke, O., \& Wirtz, B. W. (2010). Understanding consumer acceptance of mobile payment services: an empirical analysis. Electronic Commerce Research and Applications, 9(3), 209-216.

Sharif, A. M., Irani, Z., \& Weerakkody, V. (2010). Evaluating and Modelling Constructs for E-Government Decision Making. Journal of the Operational Research Society (JORS), 61(6), 928-952.

Shih, Y.-Y., \& Fang, K. (2004). The Use of a Decomposed Theory of Planned Behavior to Study Internet Banking in Taiwan. Internet Research., 14(3), 213-223.

Sivarajah, U., Irani, Z., \& Weerakkody, V. (2015). Evaluating the use and impact of web 2.0 technologies in local government. Government Information Quarterly. Available online 22 July 2015, ISSN 0740624X, doi:10.1016/j.giq.2015.06.004.

Sivarajah, U., Weerakkody, V., Waller, P., Lee, H., \& Irani, Z. (2016). Examining the Mediating Role of Participation and Open Data in Better Policy Decision Making in Local Government: The Policy Compass Approach. The Journal of Organizational Computing and Electronic Commerce (JOCEC), 64-79. doi:10.1080/10919392.2015.1125171. 
Stevens, J. (1996). Applied Multivariate Statistics for the Social Sciences. New Jersey: Lawrence ErIbaurn Associates, Incorporated.

Stokes, K., Barker, R. \& Pigott, R. (2014). Which doctors take up promising ideas? New insights from open data. Nesta. Available at: https://www.nesta.org.uk/sites/default/files/which_doctors_take_ up_promising.pdf. Accessed on: 3 Nov 2015.

Surowiecki, J. (2004). The wisdom of crowds: Why the many are smarter than the few and how collective wisdom shapes business economies, societies and nations. New York, NY: Doubleday.

Tan, M., \& Teo, T. S. H. (2000). Factors influencing the adoption of internet banking. Journal of the Association for Information Systems, 1(5), 1-42.

Tapaninen, A., Seppänen, M., \& Mäkinen, S. (2009). Characteristics of Innovation in Adopting a Renewable Residential Energy System. Journal of Systems and Information Technology., 11(4), 347-366.

Taylor, D. G., \& Strutton, D. (2010). Has E-marketing come of age? Modeling historical influences on post-adoption era internet consumer behaviors. Journal of Business Research, 63(9), 950-956.

Taylor, S., \& Todd, P. (1995). Decomposition and crossover effects in the theory of planned behavior: a study of consumer adoption intentions. International Journal of Research in Marketing, 12(2), 137-155.

Teo, T. S. H., \& Pok, S. H. (2003). Adoption of WAP-Enabled Mobile Phones among Internet Users. Omega, 31(6), 483-498.

Tornatzky, L. G., \& Klein, K. J. (1982). Innovation characteristics and innovation adoptionimplementation: a meta-analysis of findings. IEEE Transactions on engineering management, 29(1), 28-45.

Ubaldi, B. (2013), Open government data: Towards empirical analysis of open government data initiatives, OECD Working Papers on Public Governance, No. 22, OECD Publishing, Paris. doi:10.1787/5k46bj4f03s7-en

van Veenstra, A. F., \& van den Broek, T. A. (2013). Opening moves. Drivers, enablers and barriers of open data in a semi-public organization. Paper presented at the 12th Electronic Government Conference, Koblenz, Germany.

Veljković, N., Bogdanović-Dinić, S., \& Stoimenov, L. (2014). Benchmarking open government: an open data perspective. Government Information Quarterly, 31(2), 278-290.

Wang, Y.-S., Tang, T.-I., \& Tang, J.-T. D. (2001). An instrument for measuring customer satisfaction toward websites that market digital products and services. Journal of Electronic Commerce Research, 2(3), 89-102.

Wang, J., \& Senecal, S. (2007). Measuring perceived website usability. Journal of Internet Commerce, 6(4), 97-112.

Wangpipatwong, S., Chutimaskul, W., \& Papasratorn, B. (2008). Understanding Citizen's Continuance Intention to Use e-Government Website: a Composite View of Technology Acceptance Model and Computer Self-Efficacy. The Electronic Journal of e-Government, $6(1), 55-64$

Weerakkody, V., Irani, Z., Lee, H., Osman, I., \& Hindi, N. (2015). Egovernment implementation: a bird's eye view of issues relating to costs, opportunities, benefits and risks. Information Systems Frontiers, 17(4), 889-915.

Wilcox, J. (2010). Government drops first set of COINS. PublicTechnology.net, available at: http://legacy.publictechnology. net/sector/central-gov/govt-drops-first-set-coins

Zuiderwijk, A., \& Janssen, M. (2014). Open data policies, their implementation and impact: a framework for comparison. Government Information Quarterly, 31(1), 17-29.

Zuiderwijk, A., Janssen, M., Choenni, S., Meijer, R., \& Alibaks, R. S. (2012). Socio-technical impediments of open data. Electronic Journal of e-Government, 10(2), 156-172.

Zuiderwijk, A., Janssen, M., \& Dwivedi, Y. K. (2015). Government Information Quarterly. Acceptance and use predictors of open data technologies: Drawing Upon the Unified Theory of Acceptance and Use of Technology,
Vishanth Weerakkody is a Professor of Digital Governance at the Business School in Brunel University London. Prior to his academic career, Vishanth worked in a number of multinational organisations in the area of software engineering and business systems design. His research expertise lies in the area of electronic service delivery, technology adoption, diffusion, evaluation and policy modelling in the public sector context. He has published over 150 peer reviewed articles and guestedited special issues of leading journals and books on these themes. He is currently involved in several R\&D projects funded by the European Commission and other International bodies encompassing topics such as citizens' participation in public sector policy making to social innovation and life-long-learning. He is the Editor in chief of the International Journal of Electronic Government Research.

Zahir Irani is Professor of Operations and Information Management at the Business School at Brunel University London. Zahir has held various senior positions at Brunel University including that of Head of the Business School and the Department of IS and Computing. He has a $\mathrm{PhD}$ in the area of investment evaluation and undertook his leadership development at the Harvard Business School. Zahir's research interests are multidisciplinary in nature, and developed from early work on the area of evaluating investments in Manufacturing Information Systems through to more recent works in Transformational Government. He has received significant levels of funding from across the world and publishes in leading scholarly journals resulting in an $\mathrm{H}$-index of almost 60 . He is the Editor in Chief of Transforming Government: People Process and Policy.

Kawaljeet Kapoor is a Research Fellow at the Business at Brunel University London. Her present research is on the EU funded Social Innovation Drive project. She has a $\mathrm{PhD}$ in Business Management, and an MBA, both from Swansea University, Wales, and a bachelor's degree in Mechanical Engineering. Her $\mathrm{PhD}$ research was on diffusion of innovations. She has first/co-authored many publications for international refereed journals as ISF, ISM, TMR, and others. She also has three years of industry experience from working as a software engineer at Accenture Services, India.

Uthaysankar Sivarajah is a Lecturer in Operations Management at Brunel University. Prior to this role, he was a Research Fellow working on several multi-million-pound R\&D projects funded by the European Commission's Seventh Framework Programme (FP7). He is currently involved in a number of research projects which are funded by the European Commission focusing on the use of emerging technologies (Cloud Computing, Social Media) in the public sector context through to web based ICT platforms to foster Smart Cities. Sankar has a PhD in Management Studies Research from Brunel University.

Yogesh K. Dwivedi is a Professor of Digital and Social Media and Director of Research in the School of Management at Swansea University, Wales, UK. His research interests are in the area of Information Systems (IS) including the adoption and diffusion of emerging ICTs and digital and social media marketing. He has published more than 200 articles in a range of leading academic journals and conferences. He has co-edited more than 15 books on technology adoption, egovernment and IS theory and had them published by international publishers such as Springer, Routledge, and Emerald. He acted as co-editor of fifteen special issues; organised tracks, mini-tracks and panels in leading conferences; and served as programme cochair of IFIP WG 8.6 Conference. He is Associate Editor of European Journal of Marketing and Government Information Quarterly, Assistant Editor of JEIM and Senior Editor of Journal of Electronic Commerce Research. 